\title{
Effects of 3-Methyl-4-nitrophenol on the Reproductive Toxicity in Female Japanese Quail (Coturnix japonica)
}

\author{
ChunMei Li,${ }^{a, b}$ Akira K. Suzuki, ${ }^{a}$ Shinji Takahashi, ${ }^{c}$ Shinji Taneda,,${ }^{a}$ Gen Watanabe, ${ }^{d, e}$ and \\ Kazuyoshi TAYA $*, d, e$ \\ ${ }^{a}$ Environmental Nanotoxicology Section, Research Center for Environmental Risk, National Institute for Environmental \\ Studies; ${ }^{c}$ Ecological Effect Research Team, Dioxin and Environmental Endocrine Disrupter Research Project, National \\ Institute for Environmental Studies; Ibaraki 305-8506, Japan: ${ }^{b}$ Laboratory of Animal Reproduction, College of Animal \\ Science and Technology, Nanjing Agricultural University; Nanjing 210095, P. R. China: ${ }^{d}$ Laboratory of Veterinary \\ Physiology, Department of Veterinary Medicine, Faculty of Agriculture, Tokyo University of Agriculture and Technology; \\ Tokyo 183-8509, Japan: and ${ }^{e}$ Department of Basic Veterinary Science, The United Graduate School of Veterinary \\ Sciences, Gifu University; Gifu 501-1193, Japan.
}

Received July 7, 2008; accepted August 29, 2008; published online September 1, 2008

We previously showed that 3-methyl-4-nitrophenol (4-nitro-m-cresol, PNMC), a component of diesel exhaust particles and a degradation product of the insecticide fenitrothion, has reproductive toxicity in adult male and immature female Japanese quail (Coturnix japonica). Here we investigated effects of PNMC on the reproductive toxicity of mature female Japanese quail. The experiment consists of 3 periods of pretreatment, treatment, and post-treatment for $5 \mathrm{~d}$ each. The birds were reared, bred naturally for 1 week, and after $5 \mathrm{~d}$ of pretreatment, then injected intramuscularly with PNMC at doses 1,10 , or $100 \mathrm{mg} / \mathrm{kg}$ body weight daily for $5 \mathrm{~d}$. Body weight, egg weight, and hatchability did not differ among the observation periods. However, at all doses of PNMC, the egglaying rate showed a modest decrease during the treatment period, with recovery during the post-treatment period. Plasma concentrations of luteinizing hormone (LH) and estrodiol-17 $\beta$, were significantly decreased $(p<0.05)$, and plasma concentrations of progesterone significantly increased $(p<0.05)$ in birds treated with 10 and $100 \mathrm{mg} / \mathrm{kg}$ PNMC. These results suggest that PNMC have acute toxicity, and inhibited LH secretion, disturbing egg-laying in mature female quail. Our findings indicate that PNMC induces endocrine malfunction at the central level and subsequently disrupts reproductive processes in mature female quails.

Key words 3-methyl-4-nitrophenol; diesel exhaust particle; reproductive toxicity; mature Japanese quail

Endocrine-disrupting chemicals in environmental pollutants and pesticides cause mortality and reproductive abnormalities in wild birds, including abnormalities of reproductive organs and impairment of egg-laying. ${ }^{1)}$ 3-Methyl-4-nitrophenol (4-nitro- $m$-cresol, PNMC), a component of diesel exhaust particles (DEP), is a vasodilator ${ }^{2,3)}$ and has estrogenic $^{4-6)}$ and anti-androgenic ${ }^{6,7)}$ activity. Furthermore, our previous studies showed that PNMC induced marked testicular atrophy in adult male Japanese quail and significantly decreased the plasma concentrations of LH and estradiol-17 $\beta$ in immature female Japanese quail, ${ }^{8,9)}$ as well as suppressing testicular and adrenal function in immature rats. ${ }^{10,11)}$ In addition to its presence in DEP, PNMC is a degradation product of the insecticide fenitrothion, ${ }^{12)}$ a widely used pesticide with high exposure potential to humans, livestock, and poultry, in both rural and residential environments. The accumulation of PNMC from these sources could have profound effects on wildlife and human health through disruption of the endocrine and reproductive systems.

Japanese quail is extensively used in reproductive toxicity testing. Quail are representative of terrestrial birds and are accepted models for assessing both the acute and chronic effects of pesticides and other chemicals in wild birds. ${ }^{13,14)} \mathrm{Be}-$ cause no information concerning the effects of PNMC on reproductive toxicity in mature female birds is available, we here used mature female quail to examine the in vivo toxic effects of PNMC on plasma concentrations of progesterone, estradiol-17 $\beta$, basal luteinizing hormone (LH), egg-laying rate, and hatchability.

* To whom correspondence should be addressed. e-mail: taya@cc.tuat.ac.jp

\section{MATERIALS AND METHODS}

Chemicals 3-Methyl-4-nitrophenol (4-nitro-m-cresol; PNMC) was purchased from Tokyo Kasei Kogyo Co. (Tokyo, Japan).

Birds Japanese quail (Coturnix japonica) came from L (low antibody response)-selected lines, ${ }^{15,16)}$ of which chicks hatch after $17 \mathrm{~d}$ of incubation, and birds were provided with food (Kanematsu quail diet, Kanematsu Agri-tech, Ibaraki, Japan) and water ad libitum. Female birds (age, 6 month) were housed in metal cages in a controlled environment (lights on, 0500- $1900 \mathrm{~h}$; temperature, $23 \pm 2{ }^{\circ} \mathrm{C}$; humidity, $50 \pm 10 \%$; air exchanged 20 times hourly). This study was conducted in accordance with the Guiding Principles in the Use of Animals in Toxicology and was approved by the Animal Care and Use Committee of the Japanese National Institute for Environmental Studies.

Experimental Design Adult female Japanese quail were reared, naturally bred for 1 week, separated from male quail, and allocated into four groups. After $5 \mathrm{~d}$ of pretreatment, each group of birds was intramuscularly injected with PNMC at 1,10 or $100 \mathrm{mg} / \mathrm{kg}$ body weight daily for $5 \mathrm{~d}$. The $\mathrm{LD}_{50}$ of PNMC in the adult male quail was $135 \mathrm{mg} / \mathrm{kg} .{ }^{8)}$ Controls were injected with vehicle only (PBS containing 0.05\% Tween 80). The experimental period was separated into pretreatment, treatment, and post-treatment periods, each of which was $5 \mathrm{~d}$ long. Eggs were collected daily during the 5 -d pretreatment, treatment, and post-treatment periods, numbered, and weighed. The collected eggs were incubated under controlled conditions of $37.8^{\circ} \mathrm{C}$ and $60 \%$ relative humidity 
with turning once each hour, and hatchability was measured at the 18th day of incubation. The maternal female quail ( $n=6$ to 10 per group) were weighed and killed by decapitation at the morning of the end of experiment. After decapitation, blood samples were collected in heparinized plastic tubes and centrifuged at $1700 \times \boldsymbol{g}$ for $15 \mathrm{~min}$ at $4{ }^{\circ} \mathrm{C}$. Plasma was separated and stored at $-20^{\circ} \mathrm{C}$ until it was assayed for estradiol-17 $\beta$, progesterone, and LH. The liver, kidney, spleen, ovary, and oviduct were collected and weighed.

Radioimmunoassay Plasma concentrations of LH were measured with a USDA-ARS RIA kit (Beltsville, MD, U.S.A.) for chicken LH. The antiserum used was anti-avian LH (HAC-CH27-01RBP75). The hormone for iodination was chicken USDA-cLH-I-3. The results are expressed in terms of USDA-cLH-K-3. The intra- and inter-assay coefficients of variation were $5.2 \%$ and $11.2 \%$, respectively. USDA-cLH-I-3 and USDA-cLH-K-3 were kindly provided by Dr. John A. Proudman (Biotechnology and Germplasm Laboratory, Animal and Natural Resources Institute, Beltsville, MD, U.S.A.). ${ }^{17)}$ The antiserum against avian LH was kindly provided by the Biosignal Research Center of Institute for Molecular and Cellular Regulation (Gunma, Japan). ${ }^{8,18)}$ Plasma concentrations of estradiol-17 $\beta$ and progesterone were determined with a double-antibody RIA system using ${ }^{125} \mathrm{I}$-labeled radioligands as described previously. ${ }^{19)}$ The antisera against estradiol-17 $\beta$ (GDN 244) and progesterone $\left(\right.$ GDN 337) ${ }^{20)}$ were kindly provided by Dr. G. D. Niswender (Colorado State University, Fort Collins, CO, U.S.A.). The intra- and inter-assay coefficients of variation were $4.8 \%$ and $5.8 \%$ for estradiol- $17 \beta$, and $6.9 \%$ and $11.2 \%$ for progesterone, respectively.

Statistical Analysis All data are presented as mean \pm S.E.M. Statistical analysis was performed by one-way analysis of variance followed by Dunnett's multiple comparison test (StatView 5.0, SAS Institute, Cary, NC, U.S.A.). The criterion for significance was $p<0.05$.

\section{RESULTS}

Effect of PNMC on Organs and Body Weight An acute toxicologic response occurred in highest dose of $100 \mathrm{mg} / \mathrm{kg}$ PNMC treated group, of the 10 birds treated with $100 \mathrm{mg} / \mathrm{kg}$ PNMC, 4 died within $10 \mathrm{~min}$ of treatment. No birds died in the 1 and $10 \mathrm{mg} / \mathrm{kg}$ of PNMC or control groups. The surviving birds in all treatment groups grew normally, with no differences in body weights during the pretreatment, treatment, and post-treatment periods (data not shown). Daily injection of PNMC for $5 \mathrm{~d}$ did not change weights of the liver, kidney, and spleen (Table 1). PNMC at $100 \mathrm{mg} / \mathrm{kg}$ tended to decrease the weights of the ovary and oviduct, but not significantly (Table 1).

Effect of PNMC on Egg-Laying and Hatchability The egg-laying rate and egg weights of PNMC-treated birds during the pretreatment, treatment, and post-treatment periods are shown in Table 2. Egg weights did not change during any period, but PNMC treatment decreased the egg-laying rate

Table 1. Organ Weights of PNMC-Treated Mature Female Japanese Quail

\begin{tabular}{|c|c|c|c|c|}
\hline & \multicolumn{4}{|c|}{ Dose of PNMC (mg/kg) } \\
\hline & 0 & 1 & 10 & 100 \\
\hline No. of birds & 8 & 10 & 10 & 6 \\
\hline Liver (g) & $3.487 \pm 0.089$ & $3.825 \pm 0.219$ & $4.180 \pm 0.287$ & $3.926 \pm 0.477$ \\
\hline Kidney (g) & $1.631 \pm 0.072$ & $1.508 \pm 0.069$ & $1.627 \pm 0.080$ & $1.580 \pm 0.042$ \\
\hline Spleen (mg) & $66 \pm 10$ & $64 \pm 7$ & $76 \pm 6$ & $59 \pm 11$ \\
\hline Ovary (g) & $5.396 \pm 0.625$ & $6.241 \pm 0.370$ & $5.770 \pm 6.241$ & $4.322 \pm 0.665$ \\
\hline Oviduct (g) & $6.162 \pm 0.242$ & $6.713 \pm 0.404$ & $6.790 \pm 0.311$ & $5.958 \pm 0.427$ \\
\hline
\end{tabular}

The values are expressed as mean \pm S.E.M.
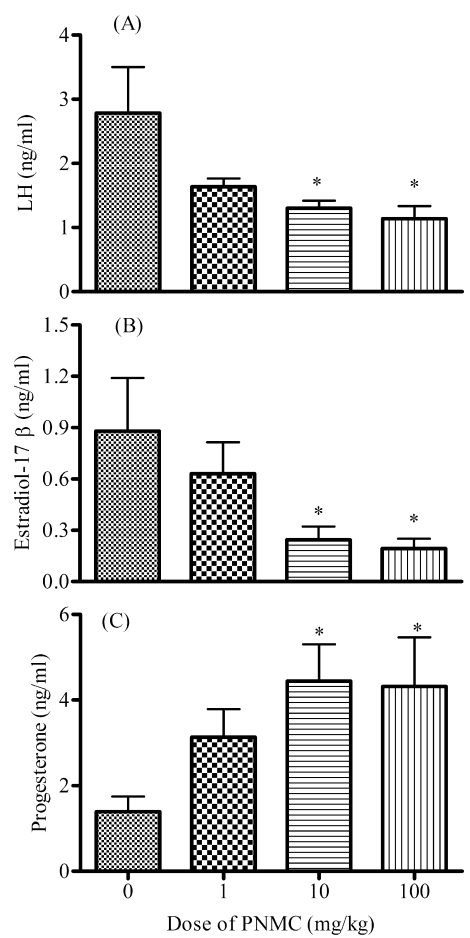

Fig. 1. Plasma Concentrations of LH (A), Estradiol-17 $\beta$ (B), and Progesterone $(\mathrm{C})$ in Mature Female Japanese Quail Treated for $5 \mathrm{~d}$ with PNMC (0, 1,10 , or $100 \mathrm{mg} / \mathrm{kg}$ Daily, Intramuscularly)

Each bar represents the mean \pm S.E.M. of 6 to 10 birds per group. $* p<0.05$ compared with value for control quail (Dunnett's multiple comparison test).

Table 2. Egg Weight and Egg-Laying Rate of PNMC-Treated Mature Female Japanese Quail during the Pretreatment, Treatment, and Post-treatment Periods

\begin{tabular}{|c|c|c|c|c|c|c|}
\hline \multirow{2}{*}{$\begin{array}{l}\text { Dose of PNMC } \\
(\mathrm{mg} / \mathrm{kg})\end{array}$} & \multicolumn{3}{|c|}{ Egg weight (g) } & \multicolumn{3}{|c|}{ Egg laying rate (no. eggs/5d) } \\
\hline & Pretreatment & Treatment & Post-treatment & Pretreatment & Treatment & Post-treatment \\
\hline 0 & $8.8 \pm 0.17$ & $9.0 \pm 0.18$ & $9.2 \pm 0.35$ & $0.57 \pm 0.12$ & $0.48 \pm 0.10$ & $0.63 \pm 0.09$ \\
\hline 1 & $9.2 \pm 0.19$ & $9.8 \pm 0.25$ & $9.6 \pm 0.16$ & $0.60 \pm 0.09$ & $0.40 \pm 0.11$ & $0.66 \pm 0.11$ \\
\hline 10 & $9.5 \pm 0.17$ & $9.6 \pm 0.19$ & $9.9 \pm 0.20$ & $0.78 \pm 0.11$ & $0.50 \pm 0.05$ & $0.52 \pm 0.10$ \\
\hline 100 & $9.8 \pm 0.20$ & $9.4 \pm 0.45$ & $9.5 \pm 0.49$ & $0.80 \pm 0.09$ & $0.32 \pm 0.10 *$ & $0.70 \pm 0.10$ \\
\hline
\end{tabular}


Table 3. Egg Hatchability of PNMC-Treated Mature Female Japanese Quail during the Pretreatment, Treatment, and Post-treatment Period

\begin{tabular}{cccc}
\hline \hline \multirow{2}{*}{$\begin{array}{c}\text { Dose of PNMC } \\
(\mathrm{mg} / \mathrm{kg})\end{array}$} & \multicolumn{3}{c}{ Hatchability (\%) } \\
\cline { 2 - 4 } & Pretreatment & Treatment & Post-treatment \\
\hline 0 & 47.8 & 57.9 & 56.0 \\
& $(11 / 23)$ & $(11 / 19)$ & $(14 / 25)$ \\
1 & 70.0 & 65.0 & 54.5 \\
& $(21 / 30)$ & $(13 / 20)$ & $(18 / 33)$ \\
10 & 61.5 & 64.0 & 80.8 \\
& $(24 / 39)$ & $(16 / 25)$ & $(21 / 26)$ \\
100 & 57.7 & 58.3 & 71.4 \\
& $(15 / 26)$ & $(7 / 12)$ & $(15 / 21)$ \\
\end{tabular}

The number of eggs that hatched/total number of eggs is given in parentheses.

throughout the treatment period, with recovery during the post-treatment period. And the egg-laying rates were significantly lower $(p<0.05)$ in the treatment period of group treated with $100 \mathrm{mg} / \mathrm{kg}$ PNMC compared with the value for pretreatment and post-treatment birds (Table 2). Hatchability was similar at all doses of PNMC throughout the experiment (Table 3).

Effect of PNMC on Plasma Concentrations of LH, Estradiol-17 $\beta$, and Progesterone Plasma concentrations of LH and estradiol-17 $\beta$ were significantly lower $(p<0.05)$ in the groups treated with 10 and $100 \mathrm{mg} / \mathrm{kg}$ PNMC than controls (Figs. 1A, B). In contrast, plasma concentrations of progesterone were significantly increased $(p<0.05)$ in the groups treated with 10 and $100 \mathrm{mg} / \mathrm{kg}$ PNMC compared with controls (Fig. 1C).

\section{DISCUSSION}

In the present study, administration of PNMC significantly decreased plasma concentrations of LH and estradiol-17 $\beta$, significantly increased plasma concentrations of progesterone, and decreased the egg-laying rate of mature female Japanese quail. The present results suggest that PNMC may have toxic effects on the hypothalamic-pituitary axis to reduce LH secretion from the pituitary gland. The decrease in circulating levels of estradiol- $17 \beta$ may be due to reduced circulating $\mathrm{LH}$.

An acute toxicologic response occurred in adult birds treated with the highest dose $(100 \mathrm{mg} / \mathrm{kg})$ of PNMC, and affected birds displayed signs of dyspnea and tremor prior to death. These results suggest that PNMC causes acute toxicity and death, possibly by a rapid decrease in blood pressure followed by ischemic shock. This proposed mechanism is consistent with the reports of the potential vasodilatory activity of PNMC. ${ }^{2,3)}$ However, none died in rats treated with the high dose of PNMC $(100 \mathrm{mg} / \mathrm{kg})$ in our previous studies. These results suggest that the sensitivity to PNMC of the quail and the rat is different and that PNMC has a high acute toxicity to the quail. In addition, it is known that PNMC inhaled by the body is metabolized by uridine diphosphate glucuronosyltransferase (UGT) and sulfotransferase, ${ }^{21)}$ and Lee et al. have demonstrated that UGT activity for PNMC in quail is less than that in the rodents. ${ }^{22)}$ These results suggest that PNMC metabolism is less efficient in the quail compared to the rodents, so that quails are more inclined to accumulate PNMC within the body, and in resulting with the higher toxi- city than the rodents.

PNMC treatment decreased the egg-laying rate of adult female quail, but the rate recovered during the post-treatment period. Previous studies have shown that PNMC has estrogenic activity in vivo and in vitro. ${ }^{4,6)}$ Estrogen is required for normal differentiation and development of the oviduct in female birds. ${ }^{23)}$ However, exposure to excessive estrogen can cause oviduct abnormalities and impaired egg-laying. ${ }^{24)}$ Furthermore, PNMC decreased plasma concentrations of $\mathrm{LH}$ in the present study, suggesting that negative-feedback has occurred due to PNMC. In contrast, here we found that administration of PNMC significantly increased plasma concentrations of progesterone, and PNMC treatment of H295R cells also increases progesterone levels. ${ }^{25)}$ We suggest that the estrogenic effects of PNMC are involved in the impairment in egg-laying of PNMC-treated adult female quail.

In conclusion, PNMC has toxic effects on the reproductive system of mature female Japanese quail through toxic effects on the hypothalamus and/or pituitary. Therefore the vast amounts of PNMC in the environment may have profound deleterious effects on the reproduction of wildlife, especially birds, and humans.

Acknowledgments We thank Dr. G. D. Niswender (Animal Reproduction and Biotechnology Laboratory, Colorado State University, Fort Collins, CO, U.S.A.) for providing antisera to estradiol-17 $\beta$ (GDN244) and progesterone (GDN377); Dr. John A. Proudman USDA-ARS, Biotechnology and Germplasm Laboratory, Beltsville, Maryland, U.S.A., for $\mathrm{LH}$ radioimmunoassay materials (radioiodination reagent and reference standard); and the Biosignal Research Center (Institute for Molecular and Cellular Regulation, Gunma, Japan) for providing antiserum against chicken LH. This study was supported in part by a Grant-in-Aid for Scientific Research (C-17510052, B1831004, P07582, and Japan-Thailand joint research) form the Japan Society for the promotion of Sciences.

\section{REFERENCES}

1) Fry D. M., Environ. Health Perspect., 103, 165-171 (1995).

2) Mori Y., Kamata K., Toda N., Hayashi H., Seki K., Taneda S., Yoshino S., Sakushima A., Sakata M., Suzuki A. K., Biol. Pharm. Bull., 26, 394-395 (2003).

3) Taneda S., Kamata K., Hayashi H., Tada N., Seki K., Sakushima A., Yoshino S., Yamaki K., Sakata M., Mori Y., Suzuki A. K., J. Health Sci., 50, 133-141 (2004).

4) Furuta C., Li C., Taneda S., Suzuki A. K., Kamata K., Watanabe G., Taya K., Endocrine, 27, 33-36 (2005).

5) Furuta C., Suzuki A. K., Taneda S., Kamata K., Hayashi H., Mori Y., Li C., Watanabe G., Taya K., Biol. Reprod., 70, 1527-1533 (2004).

6) Taneda S., Mori Y., Kamata K., Hayashi H., Furuta C., Li C., Seki K., Sakushima A., Yoshino S., Yamaki K., Watanabe G., Taya K., Suzuki A. K., Biol. Pharm. Bull., 27, 835-837 (2004).

7) Li C., Taneda S., Suzuki A. K., Furuta C., Watanabe G., Taya K., Eur J. Pharmacol., 543, $194-199$ (2006).

8) Li C., Takahashi S., Taneda S., Furuta C., Watanabe G., Suzuki A. K., Taya K., J. Endocrinol., 189, 555-564 (2006).

9) Li C., Takahashi S., Taneda S., Furuta C., Watanabe G., Suzuki A. K., Taya K., J. Reprod. Dev., 53, 673-678 (2007).

10) Li C., Taneda S., Suzuki A. K., Furuta C., Watanabe G., Taya K., J. Androl., 28, 252-258 (2006).

11) Li C., Taneda S., Suzuki A. K., Furuta C., Watanabe G., Taya K., Biol. Pharm. Bull., 30, 2376-2380 (2007).

12) Bhushan B., Samanta S. K., Chauhan A., Chakraborti A. K., Jain R. 
K., Biochem. Biophys. Res. Commun., 275, 129-133 (2000).

13) EPA (Environmental Protection Agency), "Avian Reproduction Test. OPPTS 850.2300, Public Draft, Ecological Effects Test Guidelines. EPA 712-C-96-141," United States Environmental Protection Agency, Washington, D.C., 1996.

14) Schuetzle D., Environ. Health Perspect., 47, 65-80 (1983).

15) Inooka S., Takahashi S., Takahashi H., Mizuma Y., Poult. Sci., 63, 1298-1302 (1984).

16) Takahashi S., Inooka S., Mizuma Y., Poult. Sci., 63, 595-599 (1984).

17) Krishnan K. A., Proudman J. A., Bahr J. M., Comp. Biochem. Physiol. Biochem. Mol. Biol., 108, 253-264 (1994).

18) Hattori M., Wakabayashi K., Gen. Comp. Endocrinol., 39, 215-221 (1979).

19) Taya K., Watanabe G., Sasamoto S., Jpn. J. Anim. Reprod., 31, 186-
197 (1985).

20) Gay V. L., Kerlan J. T., Arch. Androl., 1, 257-266 (1978).

21) Mackenzie P. I., Owens I. S., Burchell B., Bock K. W., Bairoch A., Belanger A., Fournel-Gigleux S., Green M., Hum D. W., Iyanagi T., Lancet D., Louisot P., Magdalou J., Chowdhury J. R., Ritter J. K., Schachter H., Tephly T. R., Tipton K. F., Nebert D. W., Pharmacogenetics, 7, 255-269 (1997).

22) Lee C. H., Kamijima M., Li C., Taneda S., Suzuki A. K., Nakajima T., Environ. Toxicol. Chem., 26, 1873-1878 (2007).

23) Palmiter R. D., Wrenn J. T., J. Cell Biol., 50, 598-615 (1971).

24) Gildersleeve R. P., Tilson H. A., Mitchell C. L., Teratology, 31, 101109 (1985).

25) Furuta C., Noda S., Li C., Suzuki A. K., Taneda S., Watanabe G., Taya K., Toxicol. Appl. Pharmacol., 229, 109-120 (2008). 